\title{
Reduction of Endogenous Kynurenic Acid Formation Enhances Extracellular Glutamate, Hippocampal Plasticity, and Cognitive Behavior
}

\author{
Michelle C Potter ${ }^{1,2}$, Greg I Elmer', Richard Bergeron ${ }^{3}$, Edson X Albuquerque ${ }^{4}$, Paolo Guidetti', \\ Hui-Qiu Wu' and Robert Schwarcz*,I \\ 'Maryland Psychiatric Research Center, Department of Psychiatry, University of Maryland School of Medicine, Baltimore, MD, USA; \\ ${ }^{2}$ Department of Biological Sciences, University of Maryland Baltimore County, Baltimore, MD, USA; ${ }^{3}$ Ottawa Health Research Institute, Ottawa, \\ ON, Canada; ${ }^{4}$ Department of Pharmacology and Experimental Therapeutics, University of Maryland School of Medicine, Baltimore, MD, USA
}

\begin{abstract}
At endogenous brain concentrations, the astrocyte-derived metabolite kynurenic acid (KYNA) antagonizes the $\alpha 7$ nicotinic acetylcholine receptor and, possibly, the glycine co-agonist site of the NMDA receptor. The functions of these two receptors, which are intimately involved in synaptic plasticity and cognitive processes, may, therefore, be enhanced by reductions in brain KYNA levels. This concept was tested in mice with a targeted deletion of kynurenine aminotransferase II (KAT II), a major biosynthetic enzyme of brain KYNA. At 21 days of age, KAT II knock-out mice had reduced hippocampal KYNA levels (-7I\%) and showed significantly increased performance in three cognitive paradigms that rely in part on the integrity of hippocampal function, namely object exploration and recognition, passive avoidance, and spatial discrimination. Moreover, compared with wild-type controls, hippocampal slices from KAT II-deficient mice showed a significant increase in the amplitude of long-term potentiation in vitro. These functional changes were accompanied by reduced extracellular KYNA (-66\%) and increased extracellular glutamate (+5l\%) concentrations, measured by hippocampal microdialysis in vivo. Taken together, a picture emerges in which a reduction in the astrocytic formation of KYNA increases glutamatergic tone in the hippocampus and enhances cognitive abilities and synaptic plasticity. Our studies raise the prospect that interventions aimed specifically at reducing KYNA formation in the brain may constitute a promising molecular strategy for cognitive improvement in health and disease. Neuropsychopharmacology (2010) 35, 1734-1742; doi:I0.1038/npp.20 10.39; published online 24 March 2010
\end{abstract}

Keywords: astrocyte; kynurenine pathway; microdialysis; $\alpha 7$ nicotinic receptor; NMDA receptor; schizophrenia

\section{INTRODUCTION}

Kynurenic acid (KYNA), a neuroinhibitory brain metabolite (Perkins and Stone, 1982), is produced by the irreversible transamination of kynurenine in a side arm of the kynurenine pathway of tryptophan degradation. In the mammalian brain, KYNA is synthesized by distinct kynurenine aminotransferases (KATs), of which KAT II has a major function (Guidetti et al, 2007a; Han et al, 2009). KAT II is localized almost exclusively in astrocytes (Guidetti et al, 2007b), which rapidly release newly formed KYNA into the extracellular milieu (Kiss et al, 2003). By competing with the endogenous agonists glycine and D-serine, KYNA may then act as an antagonist of the glycine co-agonist site of the NMDA receptor (NMDAR; Kessler et al, 1989). More likely, however, endogenous KYNA functions as an

*Correspondence: Dr R Schwarcz, Maryland Psychiatric Research Center, P.O. Box 21247, Baltimore, MD 21228 , USA, Tel: + I 410402 7635, Fax: + I 410747 2434, E-mail: rschwarc@mprc.umaryland.edu Received 30 December 2009; revised 21 February 2010; accepted I March 2010 antagonist of the allosteric-potentiating ligand site of the $\alpha 7$ nicotinic acetylcholine receptor ( $\alpha 7 \mathrm{nAChR}$ ) (Lopes et al, 2007). Alone or jointly, these receptors account for KYNA's ability to reduce brain excitation and are responsible for its neuroprotective and anticonvulsive properties (Foster $e t a l$, 1984). These effects may have a pathophysiologically relevant function in neurodegenerative diseases such as Huntington disease and Alzheimer disease, which present with abnormal brain KYNA levels (see Vámos et al, 2009 for review).

By virtue of its ability to inhibit the NMDAR and the $\alpha 7 \mathrm{nAChR}$, endogenous KYNA might also be involved in cognitive functions. Both these receptors are critical for physiological processes underlying learning, memory and, more generally, synaptic plasticity (MacDonald et al, 2006; Albuquerque et al, 2009). Therefore, fluctuations in KYNA levels can be envisioned to influence these and related phenomena. This concept is supported by studies showing that increases in brain KYNA levels, caused by the administration of kynurenine or by shifting kynurenine pathway metabolism toward enhanced KYNA formation, result in cognitive impairments in experimental animals. 
For example, elevated KYNA levels disrupt prepulse inhibition and auditory sensory gating (Shepard et al, 2003; Erhardt et al, 2004) and induce deficits in contextual learning and memory (Chess and Bucci, 2006; Chess et al, 2007). These deleterious effects of KYNA model aspects of cognitive deficits observed in schizophrenia and are, therefore, especially interesting in view of the fact that schizophrenia patients present with increased KYNA levels in brain and cerebrospinal fluid (Erhardt et al, 2001; Schwarcz et al, 2001).

This study was designed to test the complementary hypothesis, namely that a selective reduction in endogenous KYNA levels will, conversely, improve cognitive abilities. To this end, we generated mice with a targeted deletion of KAT II (KAT II knock-out (KO) mice; FVB/N background) and compared biochemical, behavioral, and electrophysiological characteristics of these mutant animals with those of wild-type (WT) controls. The studies described here were conducted in, or are related to, the hippocampus, a brain area central to cognitive processing (Morris, 2006) and abundantly endowed with both NMDARs and $\alpha 7 n A C h R s$ (Monaghan et al, 1989; FabianFine et al, 2001). Using hippocampal in vivo microdialysis, we show that KAT II KO mice show the expected decrease in extracellular KYNA levels, and that this reduction is accompanied by a significant increase in extracellular glutamate. We propose that these chemical changes may be causally related to the fact that KAT II-deficient animals show improved performance in three cognition paradigms and enhanced long-term potentiation (LTP) in hippocampal tissue slices.

\section{MATERIALS AND METHODS}

\section{Animals}

Twenty-one-day-old WT and KAT II KO mice were used in all studies. To optimize the behavioral readout (Brooks et al, 2005; Pollak et al, 2005), mutant mice were generated by backcrossing homozygous $129 /$ SvEv KAT II KO mice (Yu et al, 2004) with WT FVB/N mice (Supplementary Materials and Methods; Supplementary Figure S1). Animals were housed in temperature-controlled animal facilities on a $12 \mathrm{~h} / 12 \mathrm{~h}$ light dark cycle with free access to food and water. The facilities were fully accredited by the American Association for the Accreditation of Laboratory Animal Care and the Canadian Council of Animal Care, respectively, and the experimental protocols followed the 'Principles of Laboratory Animal Care' (NIH publication No. 86-23, 1996).

\section{Chemicals}

KYNA, glutamate, and other fine biochemicals were purchased from Sigma Chemical (St Louis, MO). AP-5, NBQX, bicuculline, picrotoxin, and strychnine were obtained from RBI (Natick, MA). CGP-52532 was purchased from Tocris (Bristol, UK). All other chemicals were obtained from a variety of suppliers and were of the highest commercially available purity.

\section{Microdialysis}

Mice were anesthetized with chloral hydrate $(360 \mathrm{mg} / \mathrm{kg}$, i.p.) and mounted in a David Kopf stereotaxic frame. A guide cannula (outer diameter: $0.65 \mathrm{~mm}$ ) was implanted unilaterally over the dorsal hippocampus (AP: $1.6 \mathrm{~mm}$ posterior to bregma, L: $1.1 \mathrm{~mm}$ from midline, V: $1.1 \mathrm{~mm}$ below the skull surface) and secured to the skull with an anchor screw and acrylic dental cement. On the next day, a microdialysis probe (CMA10, Carnegie Medicin, Stockholm, Sweden; membrane length: $1 \mathrm{~mm}$ ) was inserted through the guide cannula and connected to a microinfusion pump set to a speed of $1 \mu \mathrm{l} / \mathrm{min}$ and then perfused with Ringer solution containing (in $\mathrm{mm}$ ) $\mathrm{NaCl}, 144 ; \mathrm{KCl}, 4.8 ; \mathrm{MgSO}_{4}, 1.2$; $\mathrm{CaCl}_{2}, 1.7 ; \mathrm{pH}$ 6.7. Samples were collected every $30 \mathrm{~min}$ for the duration of the experiment.

\section{Chemical Analyses}

KYNA determination in tissue. Animals were euthanized $\left(\mathrm{CO}_{2}\right)$, and their hippocampi were dissected out without delay and sonicated in ultrapure water $(1: 10, \mathrm{w} / \mathrm{v})$. A total of $100 \mu \mathrm{l}$ of the homogenate were acidified with $25 \mu \mathrm{l}$ of $6 \%$ perchloric acid. After centrifugation (10 min, $12000 \mathrm{~g}), 20 \mu \mathrm{l}$ of the supernatant were subjected to HPLC analysis, and KYNA was detected fluorimetrically (cf. Supplementary Materials and Methods). Data were analyzed using an unpaired Student's $t$-test.

KYNA and glutamate determination in microdialysate. To determine the KYNA content of microdialysis samples, $15 \mu \mathrm{l}$ of the perfusate were injected directly into the same HPLC system used for tissue analysis (see above).

The glutamate content of microdialysis samples $(15 \mu \mathrm{l})$ was determined by HPLC analysis with fluorimetric detection, as reported by Shank et al (1993) (cf. Supplementary Materials and Methods).

Microdialysis data were analyzed by two-way repeated measures ANOVA (genotype $\times$ time) followed by Bonferroni's post hoc test for multiple comparisons.

\section{Behavioral Analyses}

Object exploration and recognition test. The object exploration and recognition task (adapted from Save et al, 1992) analyzed four different parameters: locomotor activity (open field), object exploration (habituation to environment), object displacement (response to spatial change), and object recognition (response to a novel object, NO) using the arena and video recording device described in Supplementary Materials and Methods. The procedure involved seven consecutive 6-min sessions with $\sim 30 \mathrm{~s}$ inter-session intervals. All sessions were scored from the video film. Object exploration was characterized by the amount of time the subject spent in contact with, or sniffing, an object.

Data analysis was conducted as follows: genotype differences in habituation (S2-S4) were analyzed using a two-way repeated measures ANOVA (genotype $\times$ session). The capacity to recognize displaced objects (DOs) in the environment was analyzed by comparing exploration of the DOs (minus the respective baseline value for each genotype) 
using a two-way repeated measures ANOVA (genotype $\times$ session). Post hoc analysis was conducted using univariate contrast analysis. NO recognition was analyzed by one-way ANOVA (genotype), using the ratio between the time spent exploring the NO vs the average time spent on all other objects (both DOs and non-DOs).

Contextual memory. The passive avoidance apparatus had two compartments of equal size, one illuminated and the other in darkness, separated by a guillotine door (Supplementary Materials and Methods). On day 1, the animal was first placed in the illuminated compartment. The door was then opened, prompting the mouse to move rapidly into the preferred dark compartment. After the door was closed, an inescapable foot shock $(0.56 \mathrm{~mA}$ for $1 \mathrm{~s})$ was delivered through metal rods of the floor. The latency to enter the dark compartment was recorded and used as the baseline. Twenty-four hours later, the mouse was again placed in the light compartment, and the guillotine door was opened. The time from being placed in the apparatus to the time to enter the dark compartment was recorded. The passive avoidance score (test day latency minus baseline latency) was used as an index of contextual memory formation.

Data were analyzed using an unpaired Student's $t$-test to compare individual scores.

Spatial discrimination test (T-maze). The T-maze consisted of a start box $(15.3 \mathrm{~cm} \times 17.6 \mathrm{~cm})$ connected to a choice point area $(12.2 \mathrm{~cm} \times 18.0 \mathrm{~cm})$ through an arm (72.5 cm long) made from a PVC pipe $(5 \mathrm{~cm}$ diameter). This choice point in turn led to right and left goal boxes $(15.3 \mathrm{~cm} \times 17.6 \mathrm{~cm})$ through right and left arms $(72.5 \mathrm{~cm}$ long), respectively, also made from PVC pipes $(5 \mathrm{~cm}$ diameter). Manually operated gates separated the choice point area from these arms. The walls of the arms and the goal boxes were decorated with visual cues, and a round cue light indicated the goal box that contained the reinforcing sucrose reward. Photobeams were positioned at five different locations within the maze (cf. Supplementary Figure S3) to record the following parameters: (a) latency to enter the first arm from the start box (photobeam located $2 \mathrm{~cm}$ into the arm from the start box); (b) latency to enter the choice point (photobeam located $2 \mathrm{~cm}$ immediately before the decision point); (c) latency to enter the goal arms; (d) latency to reach the reinforced location; and (e) latency to reach the nonreinforced location. The time between each beam break was recorded using Med Associates equipment (St Albans, Vermont) (see Supplementary Materials and Methods; Supplementary Figure S3 for further details).

Data were analyzed using a two-way repeated measures ANOVA (genotype $\times$ trial) for all dependent variables (ie, the number of correct trials completed each day and the various latency parameters listed above). Post hoc analysis was conducted using Fisher's LSD post hoc test for multiple comparisons.

\section{Long-Term Potentiation}

Preparation of hippocampal slices. Mice were anesthetized with isofluorane and decapitated. The brain was removed and placed in a cold $\left(4{ }^{\circ} \mathrm{C}\right)$, oxygenated $\left(95 \% \mathrm{O}_{2} / 5 \% \mathrm{CO}_{2}\right)$ physiological solution, ie artificial CSF (aCSF) containing (in mM) $126 \mathrm{NaCl}, 2.5 \mathrm{KCl}, 1 \mathrm{MgCl}_{2}, 26 \mathrm{NaHCO}_{3}, 1.25$ $\mathrm{NaH}_{2} \mathrm{PO}_{4}, 2 \mathrm{CaCl}_{2}$, and 10 glucose. The osmolarity of the aCSF was adjusted to 300 mOsm and the $\mathrm{pH}$ to 7.2. A block containing the hippocampus was prepared, and $300 \mu \mathrm{m}$ coronal sections were obtained with a vibrating microtome (Leica VT 1000S, Germany). The slices were stored for $1 \mathrm{~h}$ in an oxygenated chamber at room temperature before they were used for the experiments.

Recording procedure. For recording, the slices were transferred to a submerged-type recording chamber and held securely in place by a nylon mesh. Oxygenated, warmed $\left(32-34^{\circ} \mathrm{C}\right)$ aCSF was continuously superfused at a rate of $2.5 \mathrm{ml} / \mathrm{min}$. Current- and voltage-clamp recordings were obtained with a Multiclamp 700A amplifier (Axon Instruments, Foster City, CA) under visual control using differential interference contrast and infrared video microscopy (IR-DIC; Leica DMLFSA, Germany) (see Supplementary Materials and Methods for further details).

For data analysis, the peak excitatory postsynaptic current (EPSC) amplitude was measured with respect to its baseline a few milliseconds before the stimulus artifact. Before induction, an initial baseline of current data lasting from 10 to $20 \mathrm{~min}$ was collected. Responses were monitored for at least $40 \mathrm{~min}$ after the initiation of the pairing protocol. Sample traces in the summary graphs are 5-min averages taken just before induction and between 10 and $15 \mathrm{~min}$ after induction. The normalized values from all mice were used to calculate \pm SEM. LTP magnitude was calculated from the averaged data $10 \mathrm{~min}$ before induction $v s 20$ to $30 \mathrm{~min}$ postinduction. The same time windows were used for statistical comparisons using a two-tailed, unpaired Student's $t$-test $(p<0.01)$.

\section{RESULTS}

\section{Hippocampal KYNA and Glutamate}

Compared with WT controls, KAT II KO mice showed a $71 \%$ reduction in hippocampal KYNA levels (Figure 1a) $[\mathrm{F}($ genotype $)=44.08, \mathrm{df}=31 ; p=0.0007]$. This decrease in tissue levels was paralleled by a substantial reduction in the ambient extracellular KYNA concentration (by 66\%), determined by in vivo microdialysis (Figure $1 \mathrm{~b}$ ) [F(genotype) $=52.95, \mathrm{df}=1,10 ; p=0.0001]$. Measured in the same dialysates, extracellular glutamate levels were significantly elevated in the mutant mice (by 51\%) (Figure 1c) [F(genotype $)=14.11, \mathrm{df}=1,10 ; p=0.0037]$.

\section{Behavioral Tasks}

Object exploration and recognition.

Locomotor activity component (open field): To rule out a confounding function of altered ambulatory activity in cognitive tests, we characterized locomotor behavior in an empty arena in the first session (S1) of the object exploration and recognition test. No differences in overall activity, as determined by the number of sector crossings, were found between the two genotypes (Figure 2a).

Habituation to environment (object exploration): After session S1, object exploration was assessed over three sessions (S2-S4) in which mice were allowed to freely 

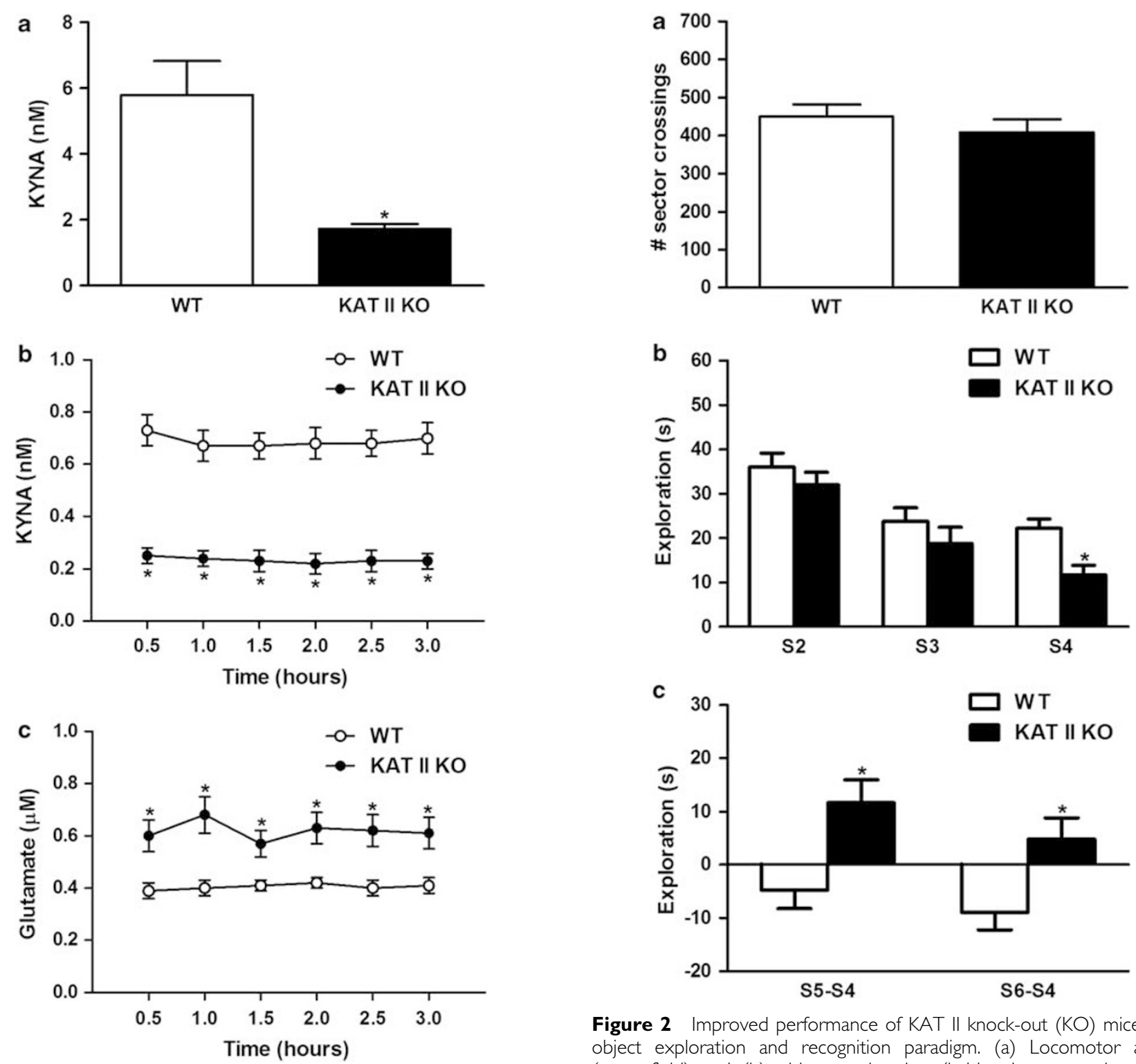

Figure 2 Improved performance of KAT II knock-out (KO) mice in an object exploration and recognition paradigm. (a) Locomotor activity (open field) and (b) object exploration (habituation to environment). Mutant mice habituated at a faster rate; (c) response to spatial change (object displacement). Compared with the baseline established in S4, KAT II KO animals spent more time than WT mice exploring the displaced object (DO) in sessions S5 and S6. Negative values reflect continued habituation in 21 -day-old wild-type (WT) mice. Data are the mean \pm SEM of 16 animals per group. ${ }^{*} p<0.05$ vs WT controls. glutamate (c) levels, respectively, in KAT $\| \mathrm{KO}$ mice and WT mice, measured by in vivo microdialysis. Data are the mean \pm SEM $(N=6$ per group). * $p<0.05$ vs WT controls.

explore five different objects, which remained in the same position (Supplementary Materials and Methods; Supplementary Figure S2). The average exploration time spent at each object was recorded during these sessions. Habituation was observed in both genotypes [WT: $\mathrm{F}($ session $)=1.2$, $\mathrm{df}=2,14 ; p=0.0045$; KAT II KO: $\mathrm{F}($ session $)=6.3, \mathrm{df}=2,14$; $p=0.0001]$; however, mutant mice habituated at a faster rate, as evidenced by an overall main effect of genotype $[\mathrm{F}$ (genotype $)=4.1, \mathrm{df}=1,30 ; p=0.0521]$. Post hoc analysis also revealed a significant difference between genotypes in session S4 $(p=0.0015)$ (Figure $2 b)$.

Response to spatial change (object displacement): To assess the animals' ability to recognize a change in spatial

configuration, two of the five objects were moved to new locations, and the average of the exploration time spent at each of these DOs was recorded during sessions S5 and S6 (cf. Supplementary Figure S2). Exploration of the DOs was related to the respective baseline values established during session S4 (ie, S5 minus S4 and S6 minus S4). KAT II KO mice showed increased exploration of the DOs in session S5 and then habituated slightly during session S6. In contrast, WT mice did not pay disproportionate attention to the DOs and continued to decrease the amount of exploration compared with session S4 (Figure 2c). Overall, there was a significant main effect of genotype on the recognition of a change in spatial configuration $[\mathrm{F}($ genotype $)=11.9, \mathrm{df}=1,30$; 
$p=0.0017]$. Post hoc analysis confirmed a significant difference between genotypes on each day $(p=0.0062$ and 0.0118 , respectively).

Response to a NO (object recognition): Session S7 consisted of replacing one of the objects with a NO (cf. Supplementary Figure S2). Both genotypes explored the NO significantly more than the objects that were present during the earlier sessions (DOs and non-DOs) [WT: $\mathrm{F}($ object $)=7.4, \quad \mathrm{df}=1,15 ; \quad p=0.0157 ; \quad$ KAT $\quad$ II $\quad$ KO: $\mathrm{F}($ object $)=4.9, \mathrm{df}=1,15 ; p=0.0426]$. The ratio of time spent exploring the NO $v s$ the average time spent exploring the non-DOs was greater in the KAT II KO mice (WT: $1.6 \pm 0.6$; KAT II KO: $2.4 \pm 0.6$ ); however, this difference was not statistically significant. These results suggest that the NO, in contrast to the DOs in session S5 and session S6, constituted a strong, salient stimulus, which prevented detection of differences between the two genotypes.

Contextual memory (passive avoidance). Contextual memory was assessed in a two-chamber (light/dark) passive avoidance paradigm. Mice were tested for their ability to remember, over a 24 -h period, the context in which an aversive stimulus (shock) was delivered. In this test, the animals are required to inhibit their natural tendency to leave a brightly lit chamber and move into a dark chamber. KAT II KO mice performed better than WT controls, as evidenced by a significantly longer latency to enter the dark side of the chamber that had earlier resulted in shock delivery $[\mathrm{F}$ (genotype $)=1.224, \mathrm{df}=31 ; p=0.0009]$ (Figure 3a). We observed no genotype difference in the physical reaction to the shock.

Spatial discrimination test (T-maze). Mice were trained in a spatial discrimination task to locate the goal box containing a reinforcing sucrose reward in a T-maze (cf. Supplementary Figure S3). WT and KAT II KO mice began the training process at equal performance levels. Overall, KAT II KO mice then made significantly more correct choices than WT mice $[\mathrm{F}$ (genotype $)=14.93$, $\mathrm{df}=1,32 ; p=0.0005]$. Post hoc analysis revealed genotypic differences beginning on day 4 until performance in WT and KAT II KO mice became statistically indistinguishable on day 10 (Fisher's LSD post hoc test for multiple comparisons) (Figure 3b). Moreover, mutant mice took significantly less time to select a maze arm once they reached the choice point of the apparatus $[\mathrm{F}$ (genotype) $=10.46, \mathrm{df}=1,32 ; p=0.003$ ] (Figure 3c). The genotype difference was not due to motivational deficits, as evidenced by comparable latencies to enter the start arm, or to motor deficits, as the two groups showed similar latencies to reach the choice point from the start box, the reinforced location, and the non-reinforced location (Supplementary Figure S4).

\section{Long-Term Potentiation}

In the Schaffer collateral/commissural synapse onto CA1 pyramidal cells, LTP is Hebbian, requiring NMDAR activation and elevation of postsynaptic calcium (Bliss and Lømo, 1973; Cummings et al, 1996). LTP was induced in CA1 pyramidal cells using a pairing protocol consisting of
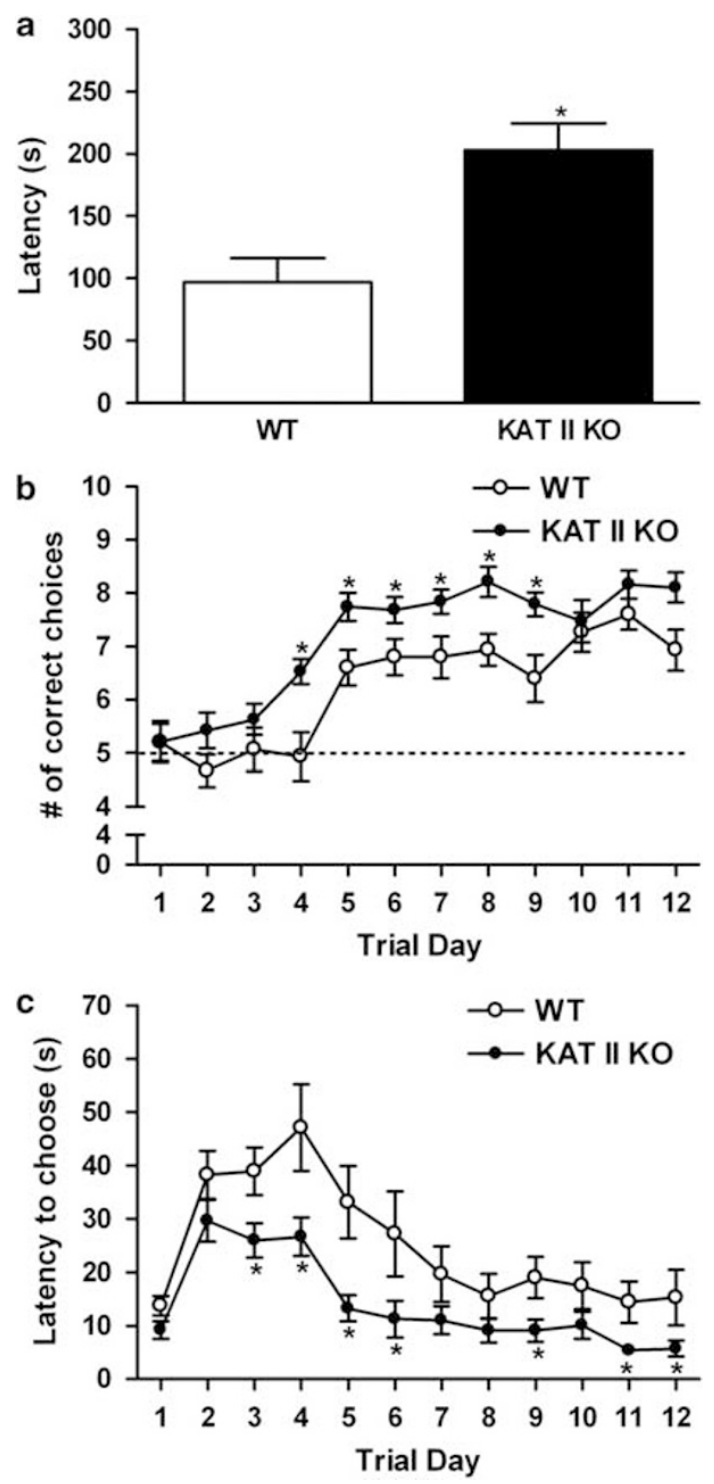

Figure 3 Improved performance of KAT \| knock-out (KO) mice in passive avoidance (contextual memory) and spatial discrimination (T-maze) tests. (a) Performance of KAT II KO and wild-type (WT) mice in a passive avoidance paradigm. Latency is defined as the difference between the times taken to enter the dark compartment on the two test days. Data are the mean \pm SEM of 16 KAT II KO and $17 \mathrm{WT}$ mice. * $<<0.05$ vs WT controls. (b) Number of correct choices (to locate a sucrose reward from a goal box) as a function of training days in a T-maze. Mice were 21 days old on the first day of the trial. Five correct choices represent chance (dashed line). (c) Latency to choose either the reinforced or the non-reinforced arm. Data in (b, c) are the mean \pm SEM of 19 KAT $\|$ KO and I5 WT mice. *p $<0.05$ vs WT controls.

three brief high-frequency tetani $(50$ pulses at $100 \mathrm{~Hz}, 4 \mathrm{~s}$ intervals), applied at the end of a 3 min depolarization at $0 \mathrm{mV}$. Slices obtained from WT mice showed an increase of $126 \pm 12 \%(N=12 ; p<0.05)$ above the baseline of synaptic responses, lasting for more than $40 \mathrm{~min}$ (Figure $4 \mathrm{a}$ ). This LTP was NMDAR-dependent as it was prevented by DL-2-amino-5-phosphonovaleric acid (AP-5, $50 \mu \mathrm{M} ;-10 \pm 9 \%$ of baseline; $N=5$; Figure 4a). Using the same protocol, we observed a substantial increase in the amplitude of LTP in 

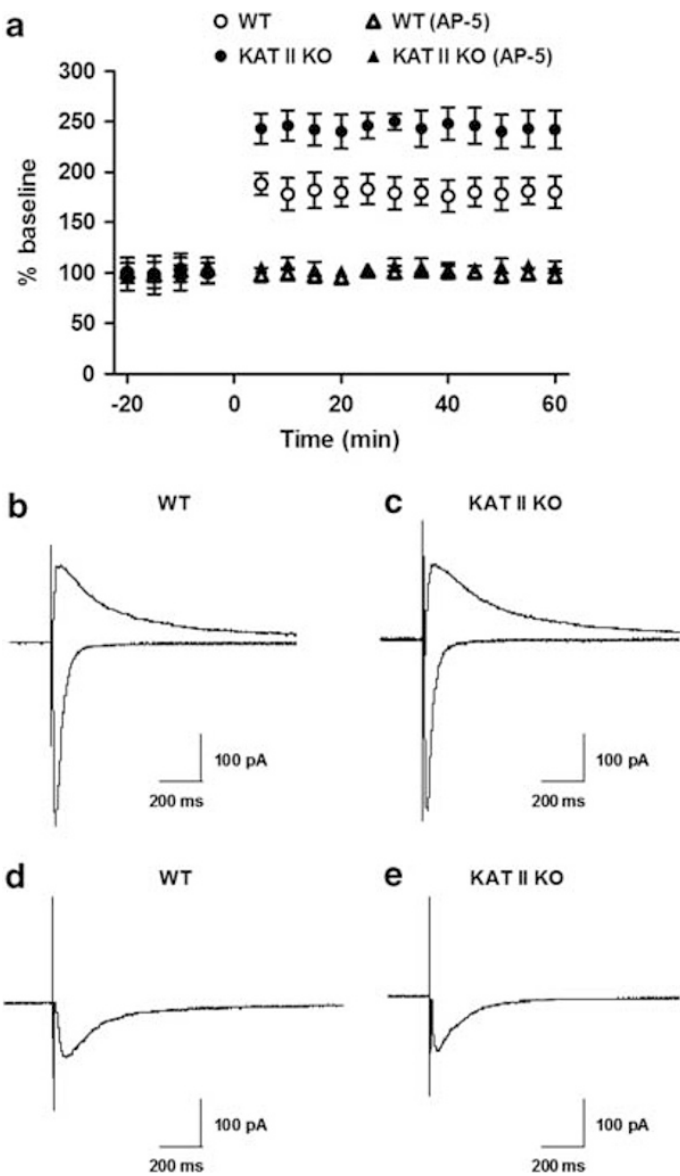

Figure 4 Enhanced LTP amplitude in hippocampal slices obtained from 2I-28-day-old KAT II knock-out (KO) and age-matched wild-type (WT) mice. (a) All values are expressed relative to the baseline, ie the average of the responses during a $10 \mathrm{~min}$ period before LTP induction. Each point represents the average of the responses recorded in $60 \mathrm{~s}$. Application of the NMDAR antagonist AP-5 $(50 \mu \mathrm{M})$ blocked LTP in slices from either genotype. Data are the mean \pm SEM ( 12 slices per group). $* 0<0.05$ vs WT controls. No significant genotypic differences were observed in NMDAR properties (resting membrane potential, firing pattern, and action potential amplitude) (b, c) or the AMPAR/NMDAR ratio (using average peak EPSCs at $+40 \mathrm{mV})(\mathrm{d}, \mathrm{e})$.

slices from mutant mice ( $248 \pm 21 \%$ above baseline; $N=12$; $p<0.05)$. The enhanced LTP in mutant mice was significantly greater than in WT controls $(p<0.005)$ and was also prevented by $50 \mu \mathrm{M} \mathrm{AP-5}$ (Figure $4 \mathrm{a}$ ).

Next, we compared additional electrophysiological characteristics of CA1 pyramidal cells in WT and KAT II KO animals. Current-clamp experiments, performed using aCSF containing low $\mathrm{Mg}^{2+}(0.1 \mathrm{mM})$, bicuculline $(20 \mu \mathrm{M})$, picrotoxin $(50 \mu \mathrm{M})$, CGP-52532 $(10 \mu \mathrm{M})$, strychnine $(2 \mu \mathrm{M})$, and NBQX $(10 \mu \mathrm{M})$ (Bergeron et al, 2007), did not reveal significant genotypic differences in terms of resting membrane potential, firing pattern, or action potential amplitude (Figure $4 \mathrm{~b}$ and $\mathrm{c}$ ). We then measured the decay kinetics of NMDARs using the average of 25 traces and the double exponential function $y=A_{\mathrm{f}} \mathrm{e}^{-t / \tau}+A_{\mathrm{s}} \mathrm{e}^{-t / \tau}$, where $A$ is the amplitude, $\tau$ is the decay time constant, and the subscripts $f$ and $s$ denote fast and slow components, respectively. These studies failed to show a significant genotypic difference in the $10-90 \%$ rise time of NMDAR EPSCs (WT: $23.7 \pm 3.1 \mathrm{~ms}$, KAT II KO: $24.5 \pm 3.9 \mathrm{~ms}$; $N=6$ each). Moreover, no significant differences were observed in the averaged $\tau_{\mathrm{s}}$ and $\tau_{\mathrm{f}}$ values of mutant and WT mice.

In a third study, we determined the AMPAR/NMDAR ratios, using the average peak EPSCs at $+40 \mathrm{mV}$ in aCSF containing picrotoxin, CGP 52432, and strychnine. The AMPAR-mediated current was defined as the difference between the responses seen in the absence and presence of NBQX. These experiments revealed no significant genotypic difference (Figure $4 \mathrm{~d}$ and e).

\section{DISCUSSION}

We used mice with a genomic deletion of KAT II, a major enzyme of KYNA biosynthesis in the mammalian brain (Guidetti et al, 2007a), to test the hypothesis that a reduction in brain KYNA levels enhances cognitive function. Focusing on the hippocampus because of its well-recognized role in cognitive processes (Morris, 2006), we used several in vivo approaches, including the measurement of extracellular glutamate levels and performance in three behavioral tasks, and also assessed LTP in tissue slices ex vivo. Both individually and jointly, our data indicated a close association between a reduction in KYNA formation and cognitive enhancement. More generally, and similar to the conceptually related proposition of Pittaluga et al (1997), we, therefore, suggest that a decrease in cerebral KYNA synthesis may constitute a biological mechanism that results in improved cognitive performance.

The behavioral paradigms (object exploration and recognition, passive avoidance, and spatial discrimination) were chosen for their ability to probe cognitive function that relies, to a considerable extent, on hippocampus-dependent circuitry. In particular, the object exploration and recognition test is an innately driven multidimensional task that requires the subject to sequentially build a spatial representation of the environment and use it to recognize change; the contextual memory (passive avoidance) task necessitates the initial consolidation and subsequent retrieval of an aversive-event memory over a 24-h period; and the spatial discrimination task involves discriminative spatial choice and reference memory to approach and obtain a reward (Save et al, 1992; Schimanski and Nguyen, 2004; Robinson et al, 2005).

Experiments in cultured cells and tissue slices, as well as in vivo studies in animals and human beings, have documented the central function of glutamate in learning and memory. Although the identity and precise functions of the ionotropic and metabotropic glutamate receptors involved, as well as the complex inter- and intracellular processes triggered by their activation, are still being elaborated, there is general consensus that increased glutamatergic activity promotes the establishment of the permanent synaptic changes that are necessary for the acquisition or recall of information (Bannerman et al, 2006; Robbins and Murphy, 2006). This conclusion is based mainly on pharmacological studies in a large number of test systems, including the experimental endpoints studied here, showing cognitive impairments after animals are treated 
with glutamate receptor antagonists (Hauber and Schmidt, 1989; Venable and Kelly, 1990; Karasawa et al, 2008).

Pro-cognitive effects of glutamate receptor activation are more difficult to observe, though improved performance has been described under normal physiological conditions when glutamatergic activity is stimulated by endogenous or exogenous receptor agonists (Lynch and Gall, 2006; Clem et al, 2008; Singer et al, 2009). Of relevance here, increased glutamatergic tone enhances memory function in relevant model systems (Richter-Levin et al, 1995; Uslaner et al, 2009). The present study in KAT II KO mice, which shows that a decrease in KYNA levels has the same functional consequences as direct glutamate receptor stimulation, is not only consistent with this concept, but introduces reduced KYNA formation as a novel endogenous control mechanism of cognitive behavior.

The higher ambient levels of extracellular glutamate in KAT II KO mice appear to be a direct consequence of reduced KYNA synthesis. On the basis of anatomical and pharmacological studies, it is likely that this link between KYNA and glutamate involves $\alpha 7 n A C h R s$. Thus, in the hippocampus as in other brain regions, glutamatergic nerve terminals are richly endowed with $\alpha 7 \mathrm{nAChRs}$, which control neuronal glutamate release (Gray et al, 1996; Girod et al, 2000; Grilli et al, 2006); and $\alpha 7 \mathrm{nAChR}$ agonists enhance, whereas $\alpha 7 \mathrm{nAChR}$ antagonists reduce, the liberation of glutamate into the extracellular milieu (Carpenedo et al, 2001; Rassoulpour et al, 2005; Wang et al, 2006; Lagostena et al, 2008). Of importance in the context of this study, the in vivo effects of classic $\alpha 7 \mathrm{nAChR}$ antagonists are duplicated by KYNA (Carpenedo et al, 2001; Rassoulpour et al, 2005; Lopes et al, 2007), and the KYNA-induced reduction in glutamate release is neutralized by the co-administration of an $\alpha 7 \mathrm{nAChR}$ agonist (Rassoulpour et al, 2005). Moreover, the KYNA concentrations applied in these and similar in vivo studies - using KYNA-induced reductions in dopamine and acetylcholine as experimental end points (Rassoulpour et al, 2005; Zmarowski et al, 2009) - are in the endogenous, ie low- to mid-nanomolar range (cf. also Grilli et al, 2006). These concentrations are far below those required to inhibit glutamate receptors directly (Perkins and Stone, 1982; Kessler et al, 1989), especially in the presence of endogenous glycine (Hilmas et al, 2001). Thus, we assume that fluctuations in endogenous KYNA levels tonically modulate $\alpha 7 \mathrm{nAChR}$ function and glutamate release in vivo. The fact that selective $\alpha 7 \mathrm{nAChR}$ activation enhances LTP in the CA1 region (Lagostena et al, 2008) and that several $\alpha 7 \mathrm{nAChR}$ agonists reliably show pro-cognitive effects in established behavioral models including those used in this study, indirectly underscores the functional importance of the link between nicotinic stimulation and glutamatergic acitivity (Levin et al, 2006; Albuquerque et al, 2009; Roncarati et al, 2009).

Our results do not rule out additional glutamatergic adaptations in KAT II KO mice. Thus, the significantly higher amplitude response in mutant mice compared with WT controls, which was observed in our study of NMDARdependent LTP, might have been caused by genotypic differences in the probability of glutamate release, the efficiency of neuronal glutamate transporters, and/or the function of proximal astrocytes (Filosa et al, 2009). Notably, however, we ruled out the most parsimonious mechanism, namely changes in the number or ratio of postsynaptic AMPARs and NMDARs in KAT II KO mice.

In addition to its emerging function in brain physiology, abnormal KYNA levels and function have been speculatively linked to several human brain disorders with cognitive symptomatology (Schwarcz and Pellicciari, 2002; Sapko et al, 2006; Raison et al, 2009; Vámos et al, 2009). In light of the present results, KYNA might be of special relevance to the pathophysiology of schizophrenia. As mentioned earlier (cf. Introduction), brain and CSF KYNA levels are increased in the disease, and elevated brain KYNA levels in animals cause impairments that are reminiscent of the cognitive deficits seen in patients (Shepard et al, 2003; Erhardt et al, 2004; Chess and Bucci, 2006; Chess et al, 2007). By inhibiting $\alpha 7 n A C h R s$ and glutamate release, enhanced KYNA may, therefore, contribute to the hyponicotinergic and hypoglutamatergic tone that is believed to underlie the cognitive deficits seen in patients (Buchanan et al, 2007). It follows that interventions targeting kynurenine pathway metabolism to decrease KYNA synthesis in the brain may not only be effective under normal physiological conditions, but may be especially valuable for improving cognition in individuals with schizophrenia (Schwarcz and Pellicciari, 2002).

The simplest approach to lower cerebral KYNA levels in health or disease is to target the enzymatic synthesis of KYNA. Although the mammalian brain contains several aminotransferases capable of producing KYNA from its immediate bioprecursor kynurenine (Guidetti et al, 2007a; Han et al, 2009), KAT II is the most substrate specific- and, therefore, 'druggable' - of these enzymes. Moreover, only KAT II has so far been conclusively linked to brain physiology (Amori et al, 2009; Zmarowski et al, 2009; $\mathrm{Wu}$ et al, 2010), increased vulnerability to massive excitotoxic insults (Sapko et al, 2006), and, as shown in this study, cognitive function. Selective inhibition of KAT II, therefore, appears to constitute the best means to attenuate KYNA formation and at the same time enhance cognition under either physiological or pathological conditions. In light of this study, novel KAT II inhibitors with good blood-brain barrier penetration will hopefully soon take the place of first-generation compounds, which do not enter the brain after peripheral administration (Pellicciari et al, 2006).

\section{ACKNOWLEDGEMENTS}

We dedicate this work to our friend Dr Paolo Guidetti, who sadly passed away on 28 December 2007. We thank Donna Calu for assistance with the T-maze experiments and Dr John Bruno for helpful comments on the manuscript. The studies were supported by USPHS grant NS25296 and a grant from the Canadian Institutes of Health Research (to RB).

\section{DISCLOSURE}

RS has received grant support from Mitsubishi-Tanabe (Yokohama, Japan) and a consultantship from Merck (West Point, PA, USA). The other authors have nothing to declare. 


\section{REFERENCES}

Albuquerque EX, Pereira EF, Alkondon M, Rogers SW (2009). Mammalian nicotinic acetylcholine receptors: from structure to function. Physiol Rev 89: 73-120.

Amori L, Wu HQ, Marinozzi M, Pellicciari R, Guidetti P, Schwarcz R (2009). Specific inhibition of kynurenate synthesis enhances extracellular dopamine levels in the rodent striatum. Neuroscience 159: 196-203.

Bannerman DM, Rawlins JN, Good MA (2006). The drugs don't work - or do they? Pharmacological and transgenic studies of the contribution of NMDA and GluR-A-containing AMPA receptors to hippocampal-dependent memory. Psychopharmacology 188: 552-566.

Bergeron R, Imamura Y, Frangioni JV, Greene RW, Coyle JT (2007). Endogenous N-acetylaspartylglutamate reduced NMDA receptor-dependent current neurotransmission in the CA1 area of the hippocampus. J Neurochem 100: 346-357.

Bliss TV, Lømo T (1973). Long-lasting potentiation of synaptic transmission in the dentate area of the anaesthetized rabbit following stimulation of the perforant path. J Physiol 232: 331-356.

Brooks SP, Pask T, Jones L, Dunnett SB (2005). Behavioural profiles of inbred mouse strains used as transgenic backgrounds. II: cognitive tests. Genes Brain Behav 4: 307-317.

Buchanan RW, Freedman R, Javitt DC, Abi-Dargham A, Lieberman JA (2007). Recent advances in the development of novel pharmacological agents for the treatment of cognitive impairments in schizophrenia. Schizophr Bull 33: 1120-1130.

Carpenedo R, Pittaluga A, Cozzi A, Attucci S, Galli A, Raiteri M et al (2001). Presynaptic kynurenate-sensitive receptors inhibit glutamate release. Eur J Neurosci 13: 2141-2147.

Chess AC, Bucci DJ (2006). Increased concentration of cerebral kynurenic acid alters stimulus processing and conditioned responding. Behav Brain Res 170: 326-332.

Chess AC, Simoni MK, Alling TE, Bucci DJ (2007). Elevations of endogenous kynurenic acid produce spatial working memory deficits. Schizophr Bull 33: 797-804.

Clem RL, Celikel T, Barth AL (2008). Ongoing in vivo experience triggers synaptic metaplasticity in the neocortex. Science 319: 101-104.

Cummings JA, Mulkey RM, Nicoll RA, Malenka RC (1996). Ca2+ signaling requirements for long-term depression in the hippocampus. Neuron 16: 825-833.

Erhardt S, Schwieler L, Emanuelsson C, Geyer M (2004). Endogenous kynurenic acid disrupts prepulse inhibition. Biol Psychiatry 56: 255-260.

Erhardt S, Blennow K, Nordin C, Skogh E, Lindström LH, Engberg G (2001). Kynurenic acid levels are elevated in the cerebrospinal fluid of patients with schizophrenia. Neurosci Lett 313: 96-98.

Fabian-Fine R, Skehel P, Errington ML, Davies HA, Sher E, Stewart MG (2001). Ultrastructural distribution of the alpha7 nicotinic acetylcholine receptor subunit in rat hippocampus. J Neurosci 21: 7993-8003.

Filosa A, Paixão S, Honsek SD, Carmona MA, Becker L, Feddersen $B$ et al (2009). Neuron-glia communication via EphA4/ephrin-A3 modulates LTP through glial glutamate transport. Nature Neurosci 12: 1285-1292.

Foster AC, Vezzani A, French ED, Schwarcz R (1984). Kynurenic acid blocks neurotoxicity and seizures induced in rats by the related brain metabolite quinolinic acid. Neurosci Lett 48: 273-278.

Girod R, Barazangi N, McGehee D, Role LW (2000). Facilitation of glutamatergic neurotransmission by presynaptic nicotinic acetylcholine receptors. Neuropharmacology 39: 2715-2725.

Gray R, Rajan AS, Radcliffe KA, Yakehiro M, Dani JA (1996). Hippocampal synaptic transmission enhanced by low concentrations of nicotine. Nature 383: 713-716.
Grilli M, Raiteri L, Patti L, Parodi M, Robino F, Raiteri M et al (2006). Modulation of the function of presynaptic alpha7 and non-alpha7 nicotinic receptors by the tryptophan metabolites, 5-hydroxyindole and kynurenate in mouse brain. Br J Pharmacol 149: 724-732.

Guidetti P, Amori L, Sapko MT, Okuno E, Schwarcz R (2007a). Mitochondrial aspartate aminotransferase: a third kynurenateproducing enzyme in the mammalian brain. J Neurochem 102: 103-111.

Guidetti P, Hoffman GE, Melendez-Ferro M, Albuquerque EX, Schwarcz R (2007b). Astrocytic localization of kynurenine aminotransferase II in the rat brain visualized by immunocytochemistry. Glia 55: 78-92.

Han Q, Robinson H, Cai T, Tagle DA, Li J (2009). Biochemical and structural properties of mouse kynurenine aminotransferase III. Mol Cell Biol 29: 784-793.

Hauber W, Schmidt WJ (1989). Effects of intrastriatal blockade of glutamatergic transmission on the acquisition of T-maze and radial maze tasks. J Neural Transm 78: 29-41.

Hilmas C, Pereira EF, Alkondon M, Rassoulpour A, Schwarcz R, Albuquerque EX (2001). The brain metabolite kynurenic acid inhibits alpha7 nicotinic receptor activity and increases nonalpha7 nicotinic receptor expression: physiopathological implications. J Neurosci 21: 7463-7473.

Karasawa J, Hashimoto K, Chaki S (2008). D-serine and a glycine transporter inhibitor improve MK-801-induced cognitive deficits in a novel object recognition test in rats. Behav Brain Res 186: 78-83.

Kessler M, Terramani T, Lynch G, Baudry M (1989). A glycine site associated with $\mathrm{N}$-methyl-D-aspartic acid receptors: characterization and identification of a new class of antagonists. J Neurochem 52: 1319-1328.

Kiss C, Ceresoli-Borroni G, Guidetti P, Zielke CL, Zielke HR, Schwarcz R (2003). Kynurenate production by cultured human astrocytes. J Neural Transm 110: 1-14.

Lagostena L, Trocme-Thibierge C, Morain P, Cherubini E (2008). The partial alpha7 nicotine acetylcholine receptor agonist $S$ 24795 enhances long-term potentiation at CA3-CA1 synapses in the adult mouse hippocampus. Neuropharmacology 54: 676-685.

Levin ED, McClernon FJ, Rezvani AH (2006). Nicotinic effects on cognitive function: behavioral characterization, pharmacological specification, and anatomic localization. Psychopharmacology 184: 523-539.

Lopes C, Pereira EF, Wu HQ, Purushottamachar P, Njar V, Schwarcz $\mathrm{R}$ et al (2007). Competitive antagonism between the nicotinic allosteric potentiating ligand galantamine and kynurenic acid at $\alpha 7^{\star}$ nicotinic receptors. J Pharmacol Exp Ther 322: 48-58.

Lynch G, Gall CM (2006). Ampakines and the threefold path to cognitive enhancement. Trends Neurosci 29: 554-562.

MacDonald JF, Jackson MF, Beazely MA (2006). Hippocampal long-term synaptic plasticity and signal amplification of NMDA receptors. Crit Rev Neurobiol 18: 71-84.

Monaghan DT, Bridges RJ, Cotman CW (1989). The excitatory amino acid receptors: their classes, pharmacology, and distinct properties in the function of the central nervous system. Annu Rev Pharmacol Toxicol 29: 365-402.

Morris RG (2006). Theories of hippocampal function. In: Andersen $\mathrm{P}$, Morris R, Amaral D, Bloss T, O'Keefe J (eds). The Hippocampus Book. Oxford University Press: New York. pp 581-713.

Pellicciari R, Rizzo RC, Costantino G, Marinozzi M, Amori L, Guidetti $\mathrm{P}$ et al. (2006). Modulators of the kynurenine pathway of tryptophan metabolism. Synthesis and preliminary biological evaluation of (S)-4-(ethylsulfonyl)benzoylalanine, a potent and selective kynurenine aminotransferase II (KAT II) inhibitor. ChemMedChem 1: 528-531. 
Perkins MN, Stone TW (1982). An iontophoretic investigation of the actions of convulsant kynurenines and their interaction with the endogenous excitant quinolinic acid. Brain Res 247: 184-187.

Pittaluga A, Vaccari D, Raiteri M (1997). The 'kynurenate test', a biochemical assay for putative cognition enhancers. J Pharmacol Exp Ther 283: 82-90.

Pollak DD, Scharl T, Leisch F, Herkner K, Villar SR, Hoeger H et al (2005). Strain-dependent regulation of plasticity-related proteins in the mouse hippocampus. Behav Brain Res 165: 240-246.

Raison CL, Dantzer R, Kelley KW, Lawson MA, Woolwine BJ, Vogt G et al (2009). CSF concentrations of brain tryptophan and kynurenines during immune stimulation with IFN-alpha: relationship to CNS immune responses and depression. Mol Psychiatry print copy in press (originally published online 17 November 2009).

Rassoulpour A, Wu H-Q, Ferré S, Schwarcz R (2005). Nanomolar concentrations of kynurenic acid reduce extracellular dopamine levels in the striatum. J Neurochem 93: 762-765.

Richter-Levin G, Canevari L, Bliss TV (1995). Long-term potentiation and glutamate release in the dentate gyrus: links to spatial learning. Behav Brain Res 66: 37-40.

Robbins TW, Murphy ER (2006). Behavioural pharmacology: 40+ years of progress, with a focus on glutamate receptors and cognition. Trends Pharmacol Sci 27: 141-148.

Robinson S, Sandstrom SM, Denenberg VH, Palmiter RD (2005). Distinguishing whether dopamine regulates liking, wanting, and/ or learning about rewards. Behav Neurosci 119: 5-15.

Roncarati R, Scali C, Comery TA, Grauer SM, Aschmi S, Bothmann $\mathrm{H}$ et al (2009). Procognitive and neuroprotective activity of a novel alpha7 nicotinic acetylcholine receptor agonist for treatment of neurodegenerative and cognitive disorders. J Pharmacol Exp Ther 329: 459-468.

Sapko MT, Guidetti P, Yu P, Tagle DA, Pellicciari R, Schwarcz R (2006). Endogenous kynurenate controls the vulnerability of striatal neurons to quinolinate: implications for Huntington's disease. Exp Neurol 197: 31-40.

Save E, Poucet B, Foreman N, Buhot MC (1992). Object exploration and reactions to spatial and nonspatial changes in hooded rats following damage to parietal cortex or hippocampal formation. Behav Neurosci 106: 447-456.

Schimanski LA, Nguyen PV (2004). Multidisciplinary approaches for investigating the mechanisms of hippocampus-dependent memory: a focus on inbred mouse strains. Neurosci Biobehav Rev 28: 463-483.
Schwarcz R, Rassoulpour A, Wu HQ, Medoff D, Tamminga CA, Roberts RC (2001). Increased cortical kynurenate content in schizophrenia. Biol Psychiatry 50: 521-530.

Schwarcz R, Pellicciari R (2002). Manipulation of brain kynurenines: glial targets, neuronal effects, and clinical opportunities. $J$ Pharmacol Exp Therap 303: 1-10.

Shank RP, Leo GC, Zielke HR (1993). Cerebral metabolic compartmentation as revealed by nuclear magnetic resonance analysis of D-[1-13C]glucose metabolism. J Neurochem 61: 315-323.

Shepard PD, Joy B, Clerkin L, Schwarcz R (2003). Micromolar brain levels of kynurenic acid are associated with a disruption of auditory sensory gating in the rat. Neuropsychopharmacology 28: 1454-1462.

Singer P, Yee BK, Feldon J, Iwasato T, Itohara S, Grampp T et al (2009). Altered mnemonic functions and resistance to N-methylD-aspartate receptor antagonism by forebrain conditional knockout of glycine transporter 1. Neuroscience 161: 635-654.

Uslaner JM, Parmentier-Batteur S, Flick RB, Surles NO, Lam JS, McNaughton CH et al (2009). Dose-dependent effect of CDPPB, the mGluR5 positive allosteric modulator, on recognition memory is associated with GluR1 and CREB phosphorylation in the prefrontal cortex and hippocampus. Neuropharmacology 57: $531-538$.

Vámos E, Pardutz A, Klivényi P, Toldi J, Vécsei L (2009). The role of kynurenines in disorders of the central nervous system: possibilities for neuroprotection. J Neurol Sci 283: 21-27.

Venable N, Kelly PH (1990). Effects of NMDA receptor antagonists on passive avoidance learning and retrieval in rats and mice. Psychopharmacology 100: 215-221.

Wang BW, Liao WN, Chang CT, Wang SJ (2006). Facilitation of glutamate release by nicotine involves the activation of a $\mathrm{Ca} 2+/$ calmodulin signaling pathway in rat prefrontal cortex nerve terminals. Synapse 59: 491-501.

Wu H-Q, Pereira EF, Bruno JP, Pellicciari R, Albuquerque EX, Schwarcz R (2010). The astrocyte-derived $\alpha 7$ nicotinic receptor antagonist kynurenic acid controls extracellular glutamate levels in the prefrontal cortex. J Mol Neurosci 40: 204-210.

Yu P, Di Prospero NA, Sapko MT, Cai T, Chen A, Melendez-Ferro $M$ et al (2004). Biochemical and phenotypic abnormalities in kynurenine aminotransferase II-deficient mice. Mol Cell Biol 24: 6919-6930.

Zmarowski A, Wu HQ, Brooks JM, Potter MC, Pellicciari R, Schwarcz $\mathrm{R}$ et al (2009). Astrocyte-derived kynurenic acid modulates basal and evoked cortical acetylcholine release. Eur J Neurosci 29: 529-538.

Supplementary Information accompanies the paper on the Neuropsychopharmacology website (http://www.nature.com/npp) 